\title{
Gün İçi Piyasası Elektrik Fiyat Tahmini için Eksik Verilerin Tamamlanması
}

\author{
Salih Gündüz ${ }^{1}$, Umut Uğurlu², İlkay Öksüz ${ }^{3 *}$ \\ 1 İstanbul Teknik Üniversitesi Bilgisayar ve Bilişim Fakültesi, Bilgisayar Mühendisliği, İstanbul, Turkey, (ORCID: 0000-0002-4282-7204), gunduzs20@itu.edu.tr \\ 2 Bahçeşehir Üniversitesi, İktisadi İdari Sosyal Bilimler Fakültesi, İşletme Bölümü, İstanbul, Turkey, (ORCID: 0000-0002-6183-969X), umut.ugurlu@eas.bau.edu.tr \\ 3* İstanbul Teknik Üniversitesi Bilgisayar ve Bilişim Fakültesi, Bilgisayar Mühendisliği, İstanbul, Turkey, (ORCID: 0000-0001-6478-0534), oksuzilkay@itu.edu.tr
}

(İlk Geliş Tarihi 5 Nisan 2021 ve Kabul Tarihi 27 Haziran 2021)

(DOI: $10.31590 /$ ejosat.908860)

ATIF/REFERENCE: Gündüz, S., Uğurlu, U. \& Öksüz, İ. (2021). Gün İçi Piyasası Elektrik Fiyat Tahmini için Eksik Verilerin Tamamlanması. Avrupa Bilim ve Teknoloji Dergisi, (25), 334-340.

\section{$\ddot{\mathbf{O} z}$}

Türkiye regüle elektrik piyasasında, gün içi piyasasının ticaret hacmi gün geçtikçe artmaktadır. Bu durum piyasa katılımcıları için yüksek doğrulukta tahmin yapabilmeyi önemli hale getirmektedir. Gün içi piyasasında sürekli müzayede şeklinde alışveriş yapılmaktadır. Bu çalışmada, öncelikle Türkiye Gün İçi Piyasası elektrik fiyatlarının saatlik ağırlıklı ortalamaları alınarak, veri tahmin problemine hazır hale getirilmiştir. Piyasada işlem yapılmayan saatler bulunduğundan, eksik veri problemi ile karşılaşılmıştır. Elektrik fiyat tahmin literatüründe bu problemin çözümüne yönelik bir çalışma bulunmamaktadır. Bu çalışmada fiyat tahmini için kullanılacak olan eğitim verilerindeki eksiklerin nasıl tamamlanacağı üzerinde durulmuştur. Eksik veri tamamlama yöntemleri uygulamaları karşılaştırılmış, tek değişkenli Lasso yöntemi ile tahminler yapılarak, sonuçlar raporlanmıştır. Eksik verileri tamamlayarak tahmin yapmanın sonuca istatistiksel olarak anlamlı şekilde katkısı olmuştur. Sonuçlarımız, eksik verileri Gün Öncesi Piyasası değerleri ile tamamlamanın en başarılı yöntem olduğunu göstermiştir.

Anahtar Kelimeler: Elektrik fiyat tahmini, Gün içi piyasası, Gün öncesi piyasası, Eksik veriler, Lasso.

\section{Data Imputation for Electricity Price Forecasting in the Intraday Market}

\begin{abstract}
Trading volume of the Turkish Intraday Electricity Market is rapidly increasing. This amplifies the significance of accurate electricity price forecasts for the market players. The trading method in the intraday market is continuous trading. In this study, data is prepared to use in the price forecasting by taking a weighted average of the hourly prices. Missing value problem is encountered because of the hours without transaction. To the best of our knowledge, there is no existing study which deals with this problem in the electricity price forecasting literature. In this article, we focused on imputing values for missing data to use them in the electricity price forecasting. Missing value methods are tested, forecasts are made by univariate lasso regression and the results are compared. Making forecasts by imputing data has increased the performance in a statistically significant manner. Our results showed that data imputation with dayahead prices is the best method.
\end{abstract}

Keywords: Electricity price forecasting, Intraday market, Day-ahead market, Missing data, Lasso.

*Sorumlu Yazar: oksuzilkay@itu.edu.tr 


\section{Giriş}

\subsection{Genel Açıklamalar}

1990'ların başından itibaren birçok ülkede elektrik ticareti, devlet kontrolündeki tekelci anlayıştan çıkıp liberal bir yapıya dönüşmüştür (Weron, 2014). Elektrik, ekonomik olarak verimli bir şekilde depolanamaması ve arz talep dengesinin gerekliliği açısından özel bir emtiadır (Shahidehpour ve diğ., 2002). Yapılan çalışmalar elektrik fiyatlarının öngörmesi zor dalgalanmalar içerdiğini göstermektedir (Zareipour ve diğ., 2007). Elektrik fiyatlarının dalgalı, durağan olmayan, çoklu mevsimsel ve yüksek miktarda aykırı değerler içeren yapısı tahmin edilmesini zorlaştırmaktadır (Monteiro ve di.̆ ., 2016). Yenilenebilir enerji kaynaklarının artması elektrik fiyatlarını daha da dalgalı hale getirmiştir (Lago ve diğ., 2018). Doğası gereği güç bir problem olan elektrik fiyat tahmini konusuna araştırmacıların ilgisi günden güne artış göstermiştir (Nowotarski ve Weron, 2018).

Enerjinin etkin kullanılması ile üretici ve tüketicilerin faydası için arz ve talep dengesinin anlık olarak sağlanması gerekmektedir. Günümüzde elektrik ticareti ikili anlaşmalar, gün öncesi ve gün içi ticaret şeklinde yapılmaktadır. İkili anlaşmalar uzun süreli olduğundan negatif ya da pozitif yönlü dengesizlikler oluşabilmekte, elektrik fazlası ya da azlığı söz konusu olabilmektedir. Bu dengesizlik gün öncesi ve gün içi piyasalarında giderilmeye çalışılmaktadır. Gün öncesi piyasasında katılımcılar teslimattan bir gün önce saatlik alış veya satış teklifleri vermekte ve piyasa yapıcı tarafından bir optimizasyon algoritması ile teklifler eşleştirilmektedir. Teklif verilen günün her bir saati için tekil elektrik fiyatları açıklanmaktadır. Gün öncesi piyasasına rağmen dengesizliğe düşen katılımcıları dengelemek için ise gün içi piyasası devreye girmektedir. Gün içi piyasasında işlemler sürekli olarak anlık yapılabilmekte, aynı saat için farklı fiyatlar oluşabilmekte, teklifler teslimattan bir saat öncesi gibi kısa bir süreye kadar verilebilmektedir. Bu piyasa, yapısı gereği, katılımcılarına önemli derecede esneklik sağlamaktadır. Bugüne dek elektrik piyasasındaki araştırmaların önemli bir kısmı gün öncesi elektrik fiyat tahmini hususunda yoğunlaşmıştır, fakat son zamanlarda gün içi piyasasının ticaret hacminin artması ile araştırmacıların bu alana olan ilgisi de artmıştır (Kiesel ve Paraschiv, 2017).

\subsection{Dünyada Gün İçi ve Gün Öncesi Piyasasında Yapılan Çalışmalar}

Weron (2014) elektrik fiyat tahmin yöntemlerini; oyun teorisi temelli, çok faktörlü, indirgenmiş form, istatistiksel yöntemler ve makine öğrenmesi yöntemleri olarak ayırmıştır. İstatistiksel yöntemler ve makine öğrenmesi yöntemleri diğerlerine göre daha başarılı sonuçlar göstermektedir. Birçok çalışma istatistiksel yöntemlerin başarılı sonuçlar gösterdiğini belirtse de, M4 tahmin yarışmasını melez bir model kazanmıştır (Smyl, 2020). Lago ve diğ. (2018) bu alanda geniş ölçekli bir çalışma yapmış, 27 farklı yöntemi karşılaştırmıştır. Gün öncesi piyasasında yapılan çalışmada makine öğrenmesi yöntemleri daha başarılı çıkmıştır. Elektrik fiyat tahmininde modeller tek değişkenli veya çok değişkenli olarak oluşturulabilir. Tek değişken olarak geçmiş elektrik fiyatları kullanılır. Çok değişkenli modellerde elektrik fiyatlarına ek olarak hava durumu tahmini, üretim ve talep tahmini, tatil günleri, takvim bilgileri gibi veriler ilave edilebilir; ancak yine gün öncesi piyasası için yapılan bir çalışma tek değişkenli modellerin de çok değişkenli modellere yakın ölçüde iyi sonuçlar verdiğini göstermiştir (Ziel ve Weron, 2018). Son yıllarda gün içi piyasasına yönelik araştırmaların da arttığı gözlemlenmektedir. Yapılan literatür taraması birçok piyasada gün içi elektrik tahmini çalışmalarının yöntemlerini ve sonuçlarını göstermektedir (Shinde ve Amelin, 2018). Uniejewski ve diğ. (2019) ile birlikte Narajewski ve Ziel (2019) ID 3 -Price isimli teslimata çok yakın zamanlı fiyatları kullanarak, Alman piyasasında tahmin yapmışlardır. Monteiro ve diğ. (2016) ile Andrade ve diğ. (2017) 6 oturumlu İberya piyasasında çalışmışlardır. Bu çalışmalardan birisi yapay sinir ağları, diğeri ise olasılığa dayalı tahmin üzerine olmuştur. Kulakov ve Ziel (2019) yenilenebilir enerji tahmininin elektrik fiyatları üzerindeki etkisini incelemişlerdir.

\subsection{Türkiye'de Gün İçi ve Gün Öncesi Piyasasında Yapılan Çalışmalar}

Türkiye'de 2001 yılında çıkarılan 4628 sayılı elektrik piyasası kanunuyla serbest elektrik ticaretine geçilmiştir. Elektrik piyasasındaki dönüşüm ve 2011'de gün öncesi piyasasının açılmasıyla elektrik fiyat tahmini önemli hale gelmiştir (Bicil, 2015). 2012 yılında yapılan bir çalışmada deterministik ve rassal süreçler ayrı ayrı irdelenerek tahmin yapılmış; ancak piyasa çok yeni olduğu için yeteri kadar veri ile çalışma imkânı bulunamamıştır (Talasli, 2012). Radyal tabanlı fonksiyon ağları ve yapay sinir ağları gibi yöntemler de Gün Öncesi Piyasası elektrik fiyat tahmininde uygulanmıştır. (Özyildirim ve Beyazit, 2014; Kölmek ve Navruz, 2015). Elektrik tüketim tahmininde yapılan bir çalışma da bu yöntemlerin potansiyelini göstermektedir (Aydın ve Toros, 2018). Son yıllarda popüler olan derin öğrenme yöntemlerinden yinelenen sinir ağları, istatistiksel modellere göre daha başarılı sonuçlar vermiştir (Ugurlu ve diğ., 2018a; Ugurlu ve diğ., 2018b). Transfer öğrenmesi yöntemiyle Avrupa'daki piyasalardan faydalanılarak Türkiye Piyasası'nda gün öncesi fiyat tahmini gerçekleştirilmiştir (Gunduz ve diğ., 2020). Türkiye'de gün içi piyasası ise 2015 yılında işleme başlamıştır. Türkiye gün içi piyasasında henüz çok sınırlı sayıda araştırma mevcuttur. Bu çalışmalarda yinelenen sinir ağları gün içi piyasasına uygulanmıştır (Yorulmus ve dĭg., 2018; Oksuz ve Ugurlu, 2019).

\subsection{Gün İçi Piyasasında Lasso ile Fiyat Tahmini ve Katkılarımız}

Lasso, hataların karesini minimize eden, öznitelik seçimi açısından başarılı bir yöntemdir (Tibshirani, 1996). Ziel ve diğ. (2016) çalışmalarında Alman/Avusturya EPEX marketinde sabahın erken saatleri ile akşam saatlerinin farklı özellikler gösterdiğini belirtmiştir. Alman EPEX piyasası üzerinde yapılan diğer bir çalışmada, gün öncesi fiyatı ve yakın saatlerdeki gün içi fiyatlarının sonuca etkisinin yüksek olduğu gözlemlenmiştir (Uniejewski ve diğ., 2019). Son olarak, yapılan bir diğer çalışmada naif ve lasso yöntemleri birleştirilerek, naif sonuçlara üstünlük sağlanmıştır (Marcjasz ve diğ., 2020). Tüm bu çalışmalar ve literatür taraması çalışması (Shinde, 2018) incelendiğinde, eksik verilerin tamamlanması ile ilgili bir çalışma yapılmadığı görülmüştür. $\mathrm{Bu}$ makalede, eksik verilerin tamamlanması için, zaman serisi eksik verileri tamamlama yöntemleri kullanılmıştır (Lepot ve diğ., 2017). Bu yöntemler karşılaştırılmış ve tahminlere etkisi gözlenmiştir.

Çalışmanın materyal bölümünde veri ve istatistiksel özellikler tartışılmaktadır. Yöntem bölümünde ise kullanılan tahmin ve eksik verileri tamamlama yöntemleri detaylı bir şekilde açıklanmıştır. Araştırma sonuçları ve tartışma bölümünde yapılan deneylerin sonuçları verilmiş ve bu sonuçlar değerlendirilmiştir. 
Sonuç bölümünde, çalışmanın önemi, literatüre katkısı ve gelecekte yapılabilecek çalışmalar belirtilmiştir.

\section{Materyal ve Metot}

\subsection{Materyal}

$\mathrm{Bu}$ çalışmada kullanılan veriler EPİAŞ’tan elde edilmiştir (EPİAŞ, 2020). Veriler 01/07/2015 ile 30/06/2018 tarihleri arasındaki gün içi ağırlıklı ortalama fiyat ve gün öncesi piyasa takas fiyatlarından oluşmaktadır. 01/07/2015 ile 30/06/2017 tarihleri arasındaki 2 yıl eğitim verisi, geriye kalan 1 yıl ise test verisi olarak kullanılmıştır. Modelimizin bağımlı değişkeni gün içi fiyatları olup, gün öncesi fiyatları bağımsız değişken olarak kullanılmıştır. Veriler ve uygulanan yöntemlerin kısaltmaları Tablo 1'de verilmiştir.

Tablo 1. Kisaltmalar

\begin{tabular}{l|c}
\hline Kısaltma & Açıklama \\
\hline$G \ddot{O P}$ & Gün öncesi piyasası \\
\hline$G \dot{I} P$ & Gün öncesi piyasasasısı \\
& fiyat
\end{tabular}

Şekil 1'de GÖP ve GİP'teki saatlere göre ortalamalar incelendiğinde iki eğrinin birlikte hareket ettikleri gözlenmiştir. Fiyatların günün erken saatlerinde oldukça düşüş gösterdiği, mesai saatlerinde ise yükseldiği görülmüştür. Yine Pazar günü diğer günlere göre daha düşük fiyatlar gözlemlenmektedir. Öğle arası saatlerindeki düşüşler de dikkat çekmiştir.

Tablo 2'de, ortalama fiyatların elektrik talebinin yüksek olduğu mesai saatleri içerisinde yüksek olduğu görülmüştür. 03:00-06:00 saatleri arasında talep düşük olduğundan, görece düşük ortalama fiyatlar gözlenmiştir. En yüksek ortalama fiyat saat 11:00'de, en yüksek standart sapma ise saat 14:00'de görülmüştür. En düşük değerler genelde 0'a yakın çıkmıştır. Türkiye gün içi piyasasında negatif değer oluşumuna piyasa yapıcı tarafından izin verilmemektedir. Saat 20:00 ve 21:00'deki en düşük değerler, diğer saatlere göre oldukça yüksek çıkmıştır. Ortalama ve ortanca değerlerin yakın olması dağılımın normale yakın olduğunu göstermektedir.

Tablo 2. Günün saatlerine göre gün içi elektrik fiyatları (Türk Lirast/MWh) istatistikleri

\begin{tabular}{|c|c|c|c|c|c|}
\hline $\begin{array}{l}\text { Saatle } \\
\mathbf{r}\end{array}$ & $\begin{array}{c}\text { Ortalam } \\
\mathbf{a}\end{array}$ & $\begin{array}{l}\text { Standar } \\
\text { t Sapma }\end{array}$ & $\begin{array}{c}\text { En } \\
\text { küçü } \\
\text { k }\end{array}$ & $\begin{array}{c}\text { En } \\
\text { büyük }\end{array}$ & $\begin{array}{c}\text { Ortanc } \\
\mathbf{a}\end{array}$ \\
\hline 0 & 160.13 & 33.89 & 3.77 & 238.35 & 159.65 \\
\hline 1 & 145.29 & 36.30 & 5 & 242.95 & 144.81 \\
\hline 2 & 130.80 & 37.72 & 1 & 228 & 132.23 \\
\hline 3 & 118.74 & 43.31 & 0.25 & 227.88 & 121.13 \\
\hline 4 & 114.34 & 44.63 & 0.43 & 227.42 & 117.86 \\
\hline 5 & 112.65 & 44.53 & 0.87 & 227.88 & 114.14 \\
\hline 6 & 119.40 & 50.31 & 0.15 & 230 & 125.25 \\
\hline 7 & 139.00 & 45.77 & 0.13 & 237.32 & 143.74 \\
\hline 8 & 162.33 & 46.74 & 0.1 & 249.78 & 169.69 \\
\hline 9 & 183.78 & 43.45 & 1.01 & 717.41 & 195.24 \\
\hline 10 & 188.98 & 45.76 & 6.4 & 996.71 & 196.98 \\
\hline 11 & 193.33 & 47.62 & 7.45 & $\begin{array}{c}1152.5 \\
6\end{array}$ & 200.73 \\
\hline 12 & 172.07 & 47.39 & 6.52 & 994.87 & 172.71 \\
\hline 13 & 177.50 & 45.58 & 6.6 & 792.57 & 178.45 \\
\hline 14 & 185.55 & 62.50 & 6.79 & 1777.7 & 190.00 \\
\hline 15 & 179.60 & 55.59 & 8.34 & $\begin{array}{c}1446.2 \\
1\end{array}$ & 180.82 \\
\hline 16 & 177.09 & 45.36 & 6.86 & 777.33 & 179.18 \\
\hline 17 & 168.75 & 55.17 & 6.43 & $\begin{array}{c}1141.3 \\
8\end{array}$ & 169.57 \\
\hline 18 & 165.90 & 45.66 & 8.99 & 733.49 & 169.15 \\
\hline 19 & 167.86 & 38.31 & 11.98 & 511.62 & 168.88 \\
\hline 20 & 169.34 & 34.63 & 51.05 & 470.87 & 168.68 \\
\hline 21 & 163.44 & 34.19 & 50.88 & 304.07 & 161.40 \\
\hline 22 & 153.41 & 35.23 & 5.08 & 253.16 & 151.08 \\
\hline
\end{tabular}




\begin{tabular}{l|l|l|l|l|l}
\hline 23 & 139.28 & 38.19 & 4 & 252.15 & 140.00 \\
\hline
\end{tabular}

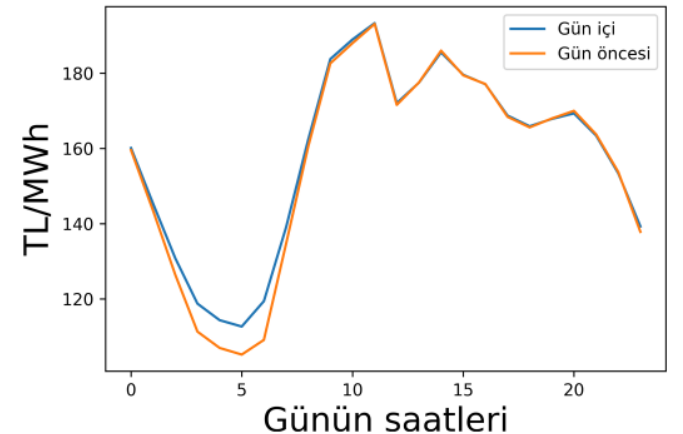

(a)

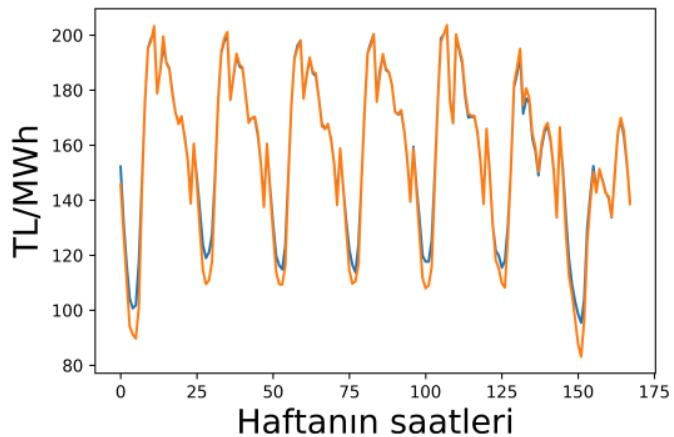

(b)

Şekil 1. Gün içi ve gün öncesi piyasasında; (a) Günün saatlerine göre ortalama elektrik fiyatlarl, (b) Haftanın saatlerine göre ortalama elektrik fiyatlart

Eğitim verileri incelendiğinde; 17544 kayittan 2359'unun $(\% 13,45)$ boş olduğu görülmüştür. Eksik veriler rastgele eksik veya rastgele olmayan şekilde eksik olarak iki şekilde ele alınmaktadır (Donders ve diğ., 2006).

\subsection{Metot}

\subsubsection{Eksik Verileri Tamamlama Yöntemleri}

Eksik verileri tamamlama, istatistiksel yöntemler ve makine öğrenmesi alanlarında bir çok çalışmanın ortak problemidir (Donders ve diğ., 2006). Bu çalışmada kullandığımız veri tek değişkenli bir veridir. Bu çalışma tekil eksik veri tamamlama yöntemlerine odaklanmıştır (Norazian ve diğ., 2008). Bu yöntemler Tablo 1'de gösterilmiştir. GİPo yönteminde tüm elde edilen değerlerin ortalaması ile eksik veriler tamamlanmıştır. Çalışmamızda kullanılan GÖP ${ }_{t}, \mathrm{GIP}_{\mathrm{GSO}}, \mathrm{GIP}_{\mathrm{HSO}}, \mathrm{GIP}_{ \pm 24}$ ve GIP $_{ \pm 168}$ yöntemlerinde deterministik bir yaklaşımla eksik veriler tamamlanmıştır. GIP $\pm t$ yöntemlerinde doldurulmak istenen değer; t saat öncesine, eğer o değer eksikse, t saat sonrasına bakılarak,

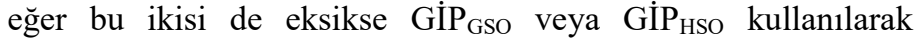
doldurulmuştur. Elektrik fiyatlarında bir gün önceki ve bir hafta önceki değerler Şekil 1'de mevcut değere çok yakın görülmüştür. $\mathrm{GÖP}_{\mathrm{t}}$ değerinin de GïP $\mathrm{t}_{\mathrm{t}}$ ile yüksek oranda ilişkili olduğu görülmüştür (Pape ve diğ., 2016). Geriye kalan DTY, ETY ve KTY ise eksik verileri tamamlamak için kullanılan interpolasyon yöntemleridir (Norazian ve diğ., 2008). Çalışmada önce gün içi ve gün öncesi arasındaki fark (spread) değerleri hesaplanıp, fark üzerinde interpolasyon yapılmıştır. DTY'de iki nokta arasındaki veriler düz bir çizgi ile tamamlanmıştır:

$$
f_{1}(x)=b_{0}+b_{1}\left(x-x_{0}\right)
$$

Burada $x$ bağımsız değişken, $x_{i}(i=0,1,2, \ldots)$ bağımsız değişkenin bilinen bir değeridir ve $b_{i}$ bilinmeyen katsayılardır. $f=$ $f_{l}$ iken Denklem 1'den,

$$
b_{0}=f\left(x_{0}\right)
$$

ve

$$
b_{1}=\frac{f\left(x_{1}\right)-f\left(x_{0}\right)}{x_{1}-x_{0}}
$$

eşitlikleri bulunmuştur.

Eğer 3 nokta biliniyorsa interpolasyon 2.dereceden polinom ile hesaplanmıştır:

$$
\begin{aligned}
f_{2}(x)=b_{0}+ & b_{1}\left(x-x_{0}\right) \\
& +b_{2}\left(x-x_{0}\right)\left(x-x_{1}\right)
\end{aligned}
$$

$b_{0}$ ve $b_{1}$ katsayıları $f=f_{2}$ alınarak Denklem 2 ve Denklem 3'den elde edilmiştir. $b_{2}$ ise Denklem 5 'teki gibi $f=f_{2}$ ile hesaplanmıştır.

$$
b_{2}=\frac{\frac{f\left(x_{2}\right)-f\left(x_{1}\right)}{x_{2}-x_{1}}-\frac{f\left(x_{1}\right)-f\left(x_{0}\right)}{x_{1}-x_{0}}}{x_{2}-x_{0}}
$$

Uygun verilere KTY uygulanabilir. Kübik interpolasyon 3. dereceden polinomlarla hesaplanmıştır:

$$
\begin{aligned}
f_{3}(x)=b_{0}+ & b_{1}\left(x-x_{0}\right) \\
& +b_{2}\left(x-x_{0}\right)\left(x-x_{1}\right) \\
& +b_{3}\left(x-x_{0}\right)\left(x-x_{1}\right)\left(x-x_{2}\right)
\end{aligned}
$$

$b_{0}, b_{1}$ ve $b_{2}, f=f_{3}$ alınarak Denklem 3-5'ten elde edilmiştir. $b_{3}$ ise şu şekilde bulunmuştur:

$$
b_{3}=\frac{\frac{f\left(x_{3}\right)-f\left(x_{2}\right)}{x_{3}-x_{2}}-\frac{f\left(x_{2}\right)-f\left(x_{1}\right)}{x_{2}-x_{1}}-\frac{f\left(x_{1}\right)-f\left(x_{0}\right)}{x_{1}-x_{0}}}{x_{3}-x_{0}}
$$

Tek değişkenli ETY boşlukların uçlarındaki erişilebilir ilk verilerden yararlanarak tüm eksik verinin hesaplanmasıyla yapılmıştır:

$$
\left\{\begin{array}{l}
y_{1} \text { if } x \leq x_{1}+\frac{\left(x_{2}-x_{1}\right)}{2} \\
y_{2} \text { if } x>x_{1}+\frac{\left(x_{2}-x_{1}\right)}{2}
\end{array}\right.
$$

\subsubsection{Tahmin Yöntemleri}

\subsubsection{Naif Model}

$\mathrm{Bu}$ modelde karşılaştırma değeri olarak gün öncesi fiyatları ölçü alınmıştır. Denklem 9'da gösterildiği gibi tahmin yapılmak 
istenen saatin ağırlıklı ortalama fiyatı, o saat için tespit edilen gün öncesi fiyatına eşitlenmiştir:

$$
G i P_{t}=G \ddot{O P} P_{t}
$$

GÖP ile GİP arasındaki yüksek korelasyondan dolayı sonuç oldukça başarılı çıkmıştır. Naif modelin sonucu tahmin algoritmaları için iyi bir başlangıç noktası ifade etmektedir (Oksuz ve Ugurlu., 2019).

\subsubsection{Lasso}

Lasso, elektrik fiyat tahmininde yaygın olarak kullanılan bir yöntem olmuştur (Ziel, 2016; Uniejewski ve diğ., 2019; Marcjasz ve diğ., 2020). Bu yöntem önemsiz öznitelikleri eleyerek girdi filtrelemesi yapmaktadır. Denklem 10, $w$ parametresi ile hataların kareleri toplamını hesaplayan fonksiyonu göstermiştir.

$$
\min _{W}\left(\frac{1}{2 * n_{\text {samples }}}\right) *\|Y-F w\|_{2}^{2}+\lambda *\|w\|_{1}
$$

Toplam örneklerin sayısı $n_{\text {samples, }} Y$ gün içi fiyat, $\mathrm{F}$ ise girdi olarak kullanılan öznitelikler ve $\lambda \geq 0$ düzgünleştirme parametresidir. Eğer $\lambda=0$ olursa denklem normal, en küçük kareler regresyonuna dönüşür. Lassoda girdi olarak kayan pencere yöntemi ile geçmiş fiyatlar kullanılmıştır (Frank ve dĭg., 2001). Tahminler eksik veriler tamamlanmadan ve farklı tamamlama yöntemleri ile tamamlanarak yapılmıştır.

\subsubsection{Değerlendirme Ölçeği}

$\mathrm{Bu}$ çalışmada değerlendirme ölçeği olarak ortalama mutlak hata kullanılmıştır. Ortalama mutlak hata (OMH) Denklem 11 'de gösterildiği gibi "N" örneklem sayısı boyunca gerçek değerler olan “ $G$ ” ile tahmin değerleri " $T$ ” kullanılarak hesaplanmıştır.

$$
O M H=\frac{1}{N} \sum_{i=1}^{N}\left|G_{i}-T_{i}\right|
$$

\section{Araştırma Sonuçları ve Tartışma}

\subsection{Kayan Pencere}

$\mathrm{Bu}$ bölümde deneylerin sonuçları verilmiştir. Lasso yönteminde girdi belirlemek için eğitim verisi üzerinde kayan pencere yöntemi kullanılmıştır. $\mathrm{Bu}$ yöntemle pencere tüm eğitim verisi üzerinde kaydırılmış, pencere içerisinde kalan değerler öznitelik vektörü; pencereden bir sonraki değer ise etiket olarak belirlenmiştir. Böylece problem bir denetimli öğrenme problemi haline getirilmiştir. Farklı uzunluklarda pencereler seçilerek tahmin testleri yapılmış, sonuçları ortalama mutlak hata olarak Tablo 3 'te gösterilmiştir.

Tablo 3.Test Verisinde farklı periyotlarda tahmin sonuçları

\begin{tabular}{c|c}
\hline Pencere Uzunluğu & OMH \\
\hline 26 & 4.58 \\
\hline 50 & 4.57 \\
\hline 74 & 4.57 \\
\hline $\mathbf{1 7 0}$ & $\mathbf{4 . 5 6}$ \\
\hline
\end{tabular}

\begin{tabular}{c|c}
\hline 338 & 4.60 \\
\hline 674 & 4.65 \\
\hline
\end{tabular}

Elektrik fiyatlarında saatlik, günlük ve haftalık mevsimsellik görülmüştür. $\mathrm{Bu}$ yüzden 24 saat ve 168 saat önceki değerlerin yüksek korelasyonda olması beklenmiştir (Wolff ve Feuerriegel, 2017). Yapılan lasso tahminlerinin katsayıları ele alındığında en önemli 10 geçmiş değer 1, 168, 24, 72, 48, 169, 73, 3, 144, 21 'inci saatler olarak sıralanmıştır. 169 ve 73 değerleri, 24 ve katları değerlerin komşu değerlerinin de önemli olabileceğini göstermiştir. Bu yüzden kayan pencere uzunluğu $24 *$ Gün +2 şeklinde belirlenmiştir. Testler sonucunda en başarılı pencere uzunluğunun 170 olduğu görülmüştür ve sonraki testlerde bu değer kullanılmıştır.

\subsection{Eksik Verileri Tamamlamanın Tahmin Sonuçlarına Etkisi}

Pencere belirlendikten sonra eksik veri tamamlama yöntemleri ile eksik veriler tamamlanmış ve tahminler yapıldıktan sonra Tablo 4'teki sonuçlar elde edilmiştir. Yalın veri (eksik veriler tamamlanmadan) ile tahminler yapıldığında $\mathrm{OMH} 4.89$ bulunmuştur. GÖP $4.56 \mathrm{OMH}$ ile en başarılı yöntem olarak gözlemlenmiştir. Interpolasyon yöntemleri veri tamamlama sayesinde yalın veriden daha iyi performans vermektedir, ancak GÖP fiyatından daha başarısız tahminlere yol açmıştır. En başarılı interpolasyon yöntemi DTY olarak gözlemlenmektedir. GÖP ve interpolasyon yöntemleri dışında naif yöntem geçilememiştir.

Tablo 4 Eksik verileri tamamlama yöntemlerinin test verilerinde Lasso tahmin sonuçlarına etkisi

\begin{tabular}{c|c}
\hline Yöntem & Ortalama Mutlak Hata \\
\hline$G \ddot{O P}{ }_{t}$ & $\mathbf{4 . 5 6}$ \\
\hline$D T Y$ & 4.59 \\
\hline ETY & 4.59 \\
\hline KTY & 4.65 \\
\hline Yalın veri & 4.89 \\
\hline GiP \pm 168 & 6.08 \\
\hline GiP ${ }_{H S O}$ & 6.23 \\
\hline GiP ${ }_{ \pm 24}$ & 6.33 \\
\hline GiP & \\
\hline GSO & 6.56 \\
\hline Genel ortalama & 7.69 \\
\hline
\end{tabular}




\subsection{Diebold -Mariano Testleri}

Tahmin sonuçlarının istatistiksel olarak anlamlı olup olmadığını göstermek için Diebold-Mariano (DM) testi uygulanmıştır (Diebold ve Mariano, 2002). Bu testte naif yöntem, yalın veri (eksik veriler tamamlanmadan) ile yapılan tahmin ve Tablo 4'teki en iyi iki yöntem karşılaştırılmıştır. Yatay eksen üzerindeki değerlerin düşey eksen üzerindeki yöntemlerden istatistiksel olarak anlamlı bir biçimde iyi olup olmadığı Şekil 2'de gösterilmiştir. Sağ eksende gösterilen p-değerlerinin 0'a yakın olması $\mathrm{x}$-ekseninde ismi yazılı olan yöntemin $\mathrm{y}$-ekseninde ismi yazılı yöntemden istatistiksel olarak anlamlı şekilde daha iyi olduğunu göstermektedir.

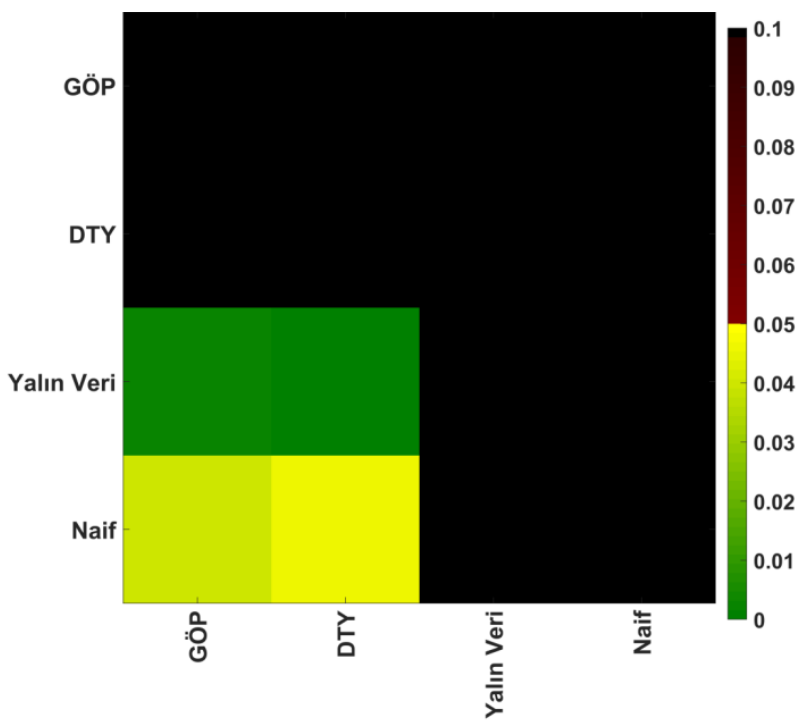

Şekil 2. Tahminde kullanılan yöntemlerin Diebold-Mariano test sonuçlart. GÖP ve DTY ile veri tamamlama Yalın veriyi kullanmaktan istatiksel anlamlı derecede iyi sonuç vermiştir.

DM testleri incelendiğinde, eksik veri tamamlamanın tahmine önemli derecede faydası olduğu görülmüştür. Naif modelin oldukça başarılı olmasından dolayı bu yöntemi geçmek zor olmuştur. GÖP ve DTY yüksek derecede olmasa da istatistiksel olarak anlamlı bir biçimde naif modeli geçebilmiştir.

\section{Sonuç}

Bu makalede gün içi elektrik fiyat tahmininde eksik verileri tamamlamadaki açık üzerinde çalışılmıştır. Gün içi elektrik fiyat tahmininin, verilerin özellikleri nedeniyle, zor bir problem olduğu bilinmektedir (Zareipour ve diğ., 2007). GÖP ile GIP verilerinin benzer özellikler içerdiği görülmüş, GÖP fiyatları eksik verileri tamamlamada kullanılmaya uygun bulunmuştur. Makalede eksik verileri tamamlama, zaman serisi problemi özelinde ele alınmıştır.

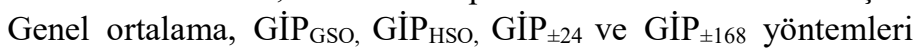
tahmin sonuçlarını olumsuz yönde etkilemişlerdir. İnterpolasyon yöntemleri olumlu katkıda bulunurken, en başarılı yöntem olarak GÖP bulunmuştur. Gelecekte gün içi piyasasında eksik verilerin tamamlanması için derin öğrenme yöntemleri denenebilir. OMH'yi azaltmak için tahmin modeli olarak derin öğrenme modelleri veya hibrit modeller kullanılabilir (Marcjasz ve diğ., 2020).

\section{Teşekkür}

Bu çalışma, İTÜ-BAP Proje No: MAB-2021-42605 uyarınca İstanbul Teknik Üniversitesi (İTÜ) Araştırma Fonu tarafından desteklenmiştir. İlkay Öksüz, Türkiye Bilimsel ve Teknolojik Araştırma Kurumu (TÜBİTAK) tarafindan 118C353 numaralı proje kapsamında desteklenmiştir. Ancak yayın ile ilgili tüm sorumluluk yayının/tebliğin sahibine aittir. TÜBİTAK'tan alınan maddi destek, yayının içeriğinin bilimsel anlamda TÜBITAK tarafindan onaylandığı anlamına gelmez.

\section{Kaynakça}

Andrade, J. R., Filipe, J., Reis, M., \& Bessa, R. J., 2017 , "Probabilistic price forecasting for day-ahead and intraday markets: Beyond the statistical model", Sustainability, Cilt 9, sayı 11, ss 1990.

Bicil, İ. M., 2015, Elektrik piyasasında fiyatlandırma ve Türkiye elektrik piyasasında fiyat tahmini, Doktora Tezi, Balıkesir Üniversitesi, Sosyal Bilimler Enstitüsü, Balıkesir.

Diebold, F. X., \& Mariano, R. S., 2002, "Comparing predictive accuracy”, Journal of Business \& economic statistics, Cilt 20, say1 1, ss. 134-144.

Donders, A. R. T., Van Der Heijden, G. J., Stijnen, T., \& Moons, K. G., 2006, "A gentle introduction to imputation of missing values", Journal of clinical epidemiology, Cilt 59, say1 10, ss. 1087-1091.

EPİAȘ, Şeffaflık

Platformu, https://seffaflik.epias.com.tr/transparency/, ziyaret tarihi:25 Ağustos 2020.

Frank, R. J., Davey, N., \& Hunt, S. P., 2001, "Time series prediction and neural networks", Journal of intelligent and robotic systems, Cilt 31, say1 1-3, ss. 91-103.

Gunduz, S., Ugurlu, U., \& Oksuz, I., 2020, “Transfer Learning for Electricity Price Forecasting”, arXiv preprint arXiv:2007.03762.

Kiesel, R., \& Paraschiv, F., 2017, "Econometric analysis of 15minute intraday electricity prices", Energy Economics, Cilt 64, ss. 77-90.

Kölmek, M. A., \& Navruz, İ., 2015, "Forecasting the day-ahead price in electricity balancing and settlement market of Turkey by using artificial neural networks", Turkish Journal of Electrical Engineering \& Computer Sciences, Cilt 23, sayı 3, Ss. 841-852.

Kulakov, S., \& Ziel, F., 2019, "The impact of renewable energy forecasts on intraday electricity prices", arXiv preprint arXiv:1903.09641.

Lago, J., De Ridder, F., \& De Schutter, B., 2018, "Forecasting spot electricity prices: Deep learning approaches and empirical comparison of traditional algorithms" Applied Energy, Cilt 221, ss. 386-405.

Lepot, M., Aubin, J. B., \& Clemens, F. H., 2017, "Interpolation in time series: An introductive overview of existing methods, their performance criteria and uncertainty assessment" Water, Cilt 9, say1 10, ss. 796.

Marcjasz, G., Uniejewski, B., \& Weron, R., 2020”, "Beating the Naïve-Combining LASSO with Naïve Intraday Electricity Price Forecasts", Energies, Cilt 13, say1 7, ss. 1667.

Monteiro, C., Ramirez-Rosado, I. J., Fernandez-Jimenez, L. A., \& Conde, P., 2016, "Short-term price forecasting models based on artificial neural networks for intraday sessions in the Iberian electricity market" Energies, Cilt 9, say1 9, ss. 721. 
Narajewski, M., \& Ziel, F., 2019, "Econometric modelling and forecasting of intraday electricity prices" Journal of Commodity Markets, Cilt 19, ss. 100107.

Norazian, M. N., Shukri, Y. A., \& Azam, R. N., 2008, "Estimation of missing values in air pollution data using single imputation techniques", ScienceAsia, Cilt 34, ss. 341-345

Nowotarski, J., \& Weron, R., 2018, "Recent advances in electricity price forecasting: A review of probabilistic forecasting”, Renewable and Sustainable Energy Reviews, Cilt 81, ss. 1548-1568.

Oksuz, I., \& Ugurlu, U., 2019, "Neural network based model comparison for intraday electricity price forecasting" Energies, Cilt 12, say1 23, ss. 4557.

Özyildirim, C., \& Beyazit, M. F., 2014, "Forecasting and modelling of electricity prices by radial basis functions: Turkish electricity market experiment" Iktisat Isletme ve Finans, Cilt 29, say1 344, ss. 31-54.

Pape, C., Hagemann, S., \& Weber, C., 2016, “Are fundamentals enough? Explaining price variations in the German day-ahead and intraday power market", Energy Economics, Cilt 54, ss. 376-387.

Shahidehpour, M., Yamin, H., \& Li, Z., 2003, "Elektrik Fiyat Tahmini”, Market operations in electric power systems: forecasting, scheduling, and risk management, John Wiley \& Sons, Wiley, ss 57-113

Shinde, P., \& Amelin, M., 2019, “A Literature Review of Intraday Electricity Markets and Prices". In 2019 IEEE Milan PowerTech, June, ss. 1-6.

Smyl, S., 2020, "A hybrid method of exponential smoothing and recurrent neural networks for time series forecasting", International Journal of Forecasting, Cilt 36, say1 1, ss. 75-85.

Talasli, I., 2012, "Stochastic Modeling of Electricity Markets", Doktora Tezi, Middle East Technical University, Financial Mathematics, Ankara.

Tibshirani, R., 1996, "Regression shrinkage and selection via the lasso" Journal of the Royal Statistical Society: Series B (Methodological), Cilt 58, sayı 1, ss. 267-288.
TOROS, H., \& Aydın, D. (2018). Prediction of Short-Term Electricity Consumption by Artificial Neural Networks Using Temperature Variables. Avrupa Bilim ve Teknoloji Dergisi, (14), 393-398.

Ugurlu, U., Oksuz, I., \& Tas, O., 2018, "Electricity price forecasting using recurrent neural networks. Energies", Cilt 11, say1 5, ss. 1255 .

Ugurlu, U., Tas, O., Kaya, A., \& Oksuz, I., 2018, “The financial effect of the electricity price forecasts' inaccuracy on a hydrobased generation company, Energies", Cilt 11, say1 8, ss. 2093.

Uniejewski, B., Marcjasz, G., \& Weron, R., 2019, “Understanding intraday electricity markets: Variable selection and very short-term price forecasting using LASSO", International Journal of Forecasting, Cilt 35, say1 4, ss. 1533-1547.

Weron, R., 2014, "Electricity price forecasting: A review of the state-of-the-art with a look into the future" International journal of forecasting, Cilt 30, say1 4, ss. 1030-1081.

Yorulmus, H., Ugurlu, U., \& Tas, O., 2018, “A Long Short Term Memory Application On The Turkish Intraday Electricity Price Forecasting", PressAcademia Procedia, Cilt 7, sayı 1, ss. 126-130.

Zareipour, H., Bhattacharya, K., \& Canizares, C. A., 2007 "Electricity market price volatility: The case of Ontario", Energy policy, Cilt 35, say1 9, ss. 4739-4748.

Ziel, F., 2016 "Forecasting electricity spot prices using lasso: On capturing the autoregressive intraday structure" IEEE Transactions on Power Systems, Cilt 31, say1 6, ss. 49774987.

Ziel, F., \& Weron, R., 2018, "Day-ahead electricity price forecasting with high-dimensional structures: Univariate vs. multivariate modeling frameworks", Energy Economics, Cilt 70, ss. 396-420. 